\title{
Evaluation of the quadrants of femoral neck-head in the cephalomedullary fixation of intertrochanteric fractures with a helical blade: Is inferior posterior quadrant also safe? A clinical study
}

\author{
Levent Karapınar, MD(D), Ali Turgut, MD (D), Mert Kumbaracı, MD(D), Anıl Koca, MD (1) \\ Department of Orthopedics and Traumatology, Tepecik Training and Research Hospital, Izmir, Turkey.
}

Preventing mechanical complications in surgically fixed intertrochanteric fractures (ITFs) is crucial both for possible morbidity and mortality. Mechanical complications can be a result of modifiable and non-modifiable factors. ${ }^{[1]}$ Non-modifiable factors are low quality of bone and fracture type (stable or unstable). Modifiable factors are usually surgeon dependent. These are quality of the reduction and correct selection and positioning of the implant.

Previously, importance of avoiding the varus reduction has been emphasized. ${ }^{[2]}$ Femoral neck is divided into three regions as superior, center, and inferior on coronal plane and anterior, center, and posterior on sagittal plane. Nine quadrants are defined after intersection of these regions. ${ }^{[3]}$ There is

Received: July 17, 2020

Accepted: October 13, 2020

Published online: January 06, 2021

Correspondence: Levent Karapınar, MD. Tepecik Eğitim ve Araştırma Hastanesi Ortopedi ve Travmatoloji Kliniği, 35020 Konak, İzmir, Türkiye.

E-mail: Ikarapinar@yahoo.com

Doi: 10.5606/ehc. 2021.78098

Citation: Karapınar L, Turgut A, Kumbaracı M, Koca A. Evaluation of the quadrants of femoral neck-head in the cephalomedullary fixation of intertrochanteric fractures with a helical blade: Is inferior posterior quadrant also safe? A clinical study. Jt Dis Relat Surg 2021;32(1):93-100.

(02021 All right reserved by the Turkish Joint Diseases Foundation

This is an open access article under the terms of the Creative Commons Attribution-NonCommercial License, which permits use, distribution and reproduction in any medium, provided the original work is properly cited and is not used for commercial purposes (http://creativecommons.org/licenses/by-nc/4.0/).

\section{ABSTRACT}

Objectives: This study aims to investigate the positioning of the helical blade to prevent mechanical complications in surgically fixed intertrochanteric fractures (ITFs).

Patients and methods: In this retrospective study, 392 patients (158 males, 234 females; mean age: $75.5 \pm 13.4$; range, 20 to 101) years) with ITFs treated in lateral decubitus position with proximal femoral nail anti-rotation in a single center between January 2009 and January 2017 were evaluated. The fractures were classified according to the Orthopedic Trauma Association classification preoperatively and grouped as stable or unstable. Postoperatively, tip-apex distance (TAD), Baumgaertner reduction criteria, and obtained quadrants were evaluated. Patients with an unstable fracture, proper TAD, and acceptable or good reduction were included in the final evaluation for statistical analysis to investigate the safest quadrant to prevent cut-out complication.

Results: Cut-out complications were observed in $19(4.8 \%)$ patients. The scenario; unstable fracture, TAD $<25 \mathrm{~mm}$, acceptable or good reduction consisted of 111 patients in total and cut-out complication occurred in four of them (3.6\%) (one in center-posterior, one in center-center, one in superior-anterior, and one in superior-center quadrants). There was no statistically significant difference between center-center, inferior-center, and inferior-posterior quadrants $(\mathrm{p}=0.49)$.

Conclusion: Inferior-posterior placement is as safe as central-central or inferior-central placement for blade fixation in the surgical treatment of ITF.

Keywords: Cephalomedullary, cut-out, helical blade, intertrochanteric fracture.

still debate on the most suitable quadrant positioning for head-neck fixation device. Center-center or inferior-center quadrants are recommended by many authors. ${ }^{[4-10]}$ Inferior-anterior ${ }^{[10]}$ and inferior-posterior quadrants were also recommended. ${ }^{[11,12]}$ Obtaining a tip-apex distance (TAD) $\leq 25 \mathrm{~mm}$ is an important factor for achieving enough mechanical stability in 
ITF. ${ }^{[13]}$ However, Kane et al., ${ }^{[5]}$ Mingo-Robinet et al., ${ }^{[14]}$ and Herman et al. ${ }^{[15]}$ stated that TAD was not the main factor for preventing mechanical complications in the use of proximal femoral nails.

When a femoral neck or ITF occurs, lower extremity tends to externally rotate. In patients with cut-out complication, head-neck fixation device (screw or helical blade) usually cuts the femoral head-neck anteriorly and superiorly. Based on these facts, we hypothesized that in patients with ITF who do not have varus reduction and whose implant's TAD was in recommended limits, obtaining the inferior-posterior quadrant implantation should also result in least cut-out complication because if the helical blade was placed in this quadrant, both the distance and the total amount of bone mass the helical blade needs to traverse for occurrence of cut-out complication would be increased. Therefore, in this study, we aimed to investigate the positioning of the helical blade to prevent mechanical complications in surgically fixed ITFs.

\section{PATIENTS AND METHODS}

In this retrospective study conducted at Tepecik Training and Research Hospital, Department of Orthopedics and Traumatology patients with an ITF who were treated surgically with a cephalomedullary implant using helical blade to fix the head-neck fragment between January 2009 and January 2017 were evaluated. There were a total of 536 patients with ITF who were treated surgically in this period. Patients who were followed-up for at least six months and who had radiographs of good quality (to ensure that required measurement and evaluations would be performed) were included. Exclusion criteria were patients with a shorter follow-up, cut-through complications, and low-quality radiographs accordingly. Finally, 392 patients (158 males, 234 females; mean age: $75.5 \pm 13.4$; range, 20 to 101 years) were included. Flowchart of the study population is shown in Figure 1. The study protocol was approved by the Tepecik Training and Research Hospital Ethics Committee (No: 2020:2/4). A written informed consent was obtained from each patient. The study was conducted in accordance with the principles of the Declaration of Helsinki.

The patients were operated in lateral decubitus position by 13 different surgeons using the same implant design of proximal femoral nail anti-rotation (PFNA) (PFNA; Synthes ${ }^{\circledR}$ Oberdorf, Switzerland).

The fractures were classified according to the Orthopedic Trauma Association (OTA) classification preoperatively. ${ }^{[16]}$ Types 31 A1 through 31 A2.1 fractures were accepted as stable, and types 31 A2.2-3 and $31 \mathrm{~A} 3$ as unstable. ${ }^{[17]}$ Postoperatively, TAD, collodiaphyseal angles (CDAs), and obtained quadrants according to Cleveland and Bosworth definition. ${ }^{[3]}$ were evaluated. Calcar referenced TAD measurement was performed in the radiographs in which helical blade was positioned in inferior quadrant. ${ }^{[18]}$ Quality of the reductions was grouped as good, acceptable, and poor according to Baumgaertner criteria. ${ }^{[4]}$ In his original study, Baumgaertner defined the good reduction as normal or slight valgus alignment in coronal plane, less than $20^{\circ}$ angulation in the lateral plane, and no more than $4 \mathrm{~mm}$ displacement in any plane. For a reduction to be defined as acceptable, it has to meet the criterion of a good reduction with respect to either alignment or displacement but not both. And finally, poor reduction met neither criterion. ${ }^{[4]}$ Measurement methods of TAD, CDA, and determination of quadrants are demonstrated in Figure 2a-f. All evaluations were performed by the same author. Reductions were grouped as varus if the obtained CDA was under $130^{\circ}$ postoperatively. ${ }^{[15]}$ Tip-apex distances were grouped as proper if the measured value was under or equal to $25 \mathrm{~mm}$.

Patients with cut-out complications were evaluated in different scenarios according to the stability of the fracture, TAD, and reduction quality (Table I). Patients with an unstable fracture, proper TAD, and acceptable or good reductions were included in final evaluation for statistical analysis to investigate the safest quadrant to prevent cut-out complication. This selection criterion was selected to standardize the other possible important surgeon dependent factors for preventing the cut-out complication.

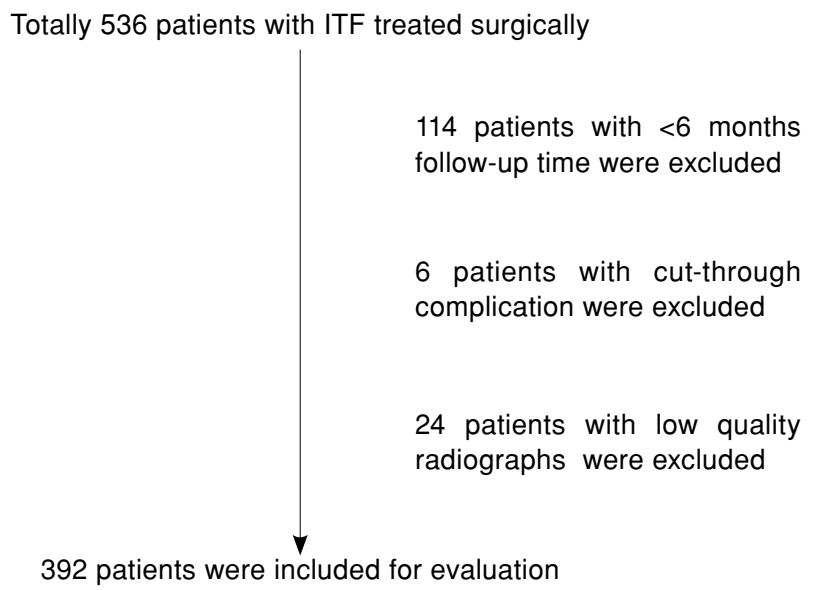

FIGURE 1. Flowchart of study population.

ITF: Intertrochanteric fracture. 

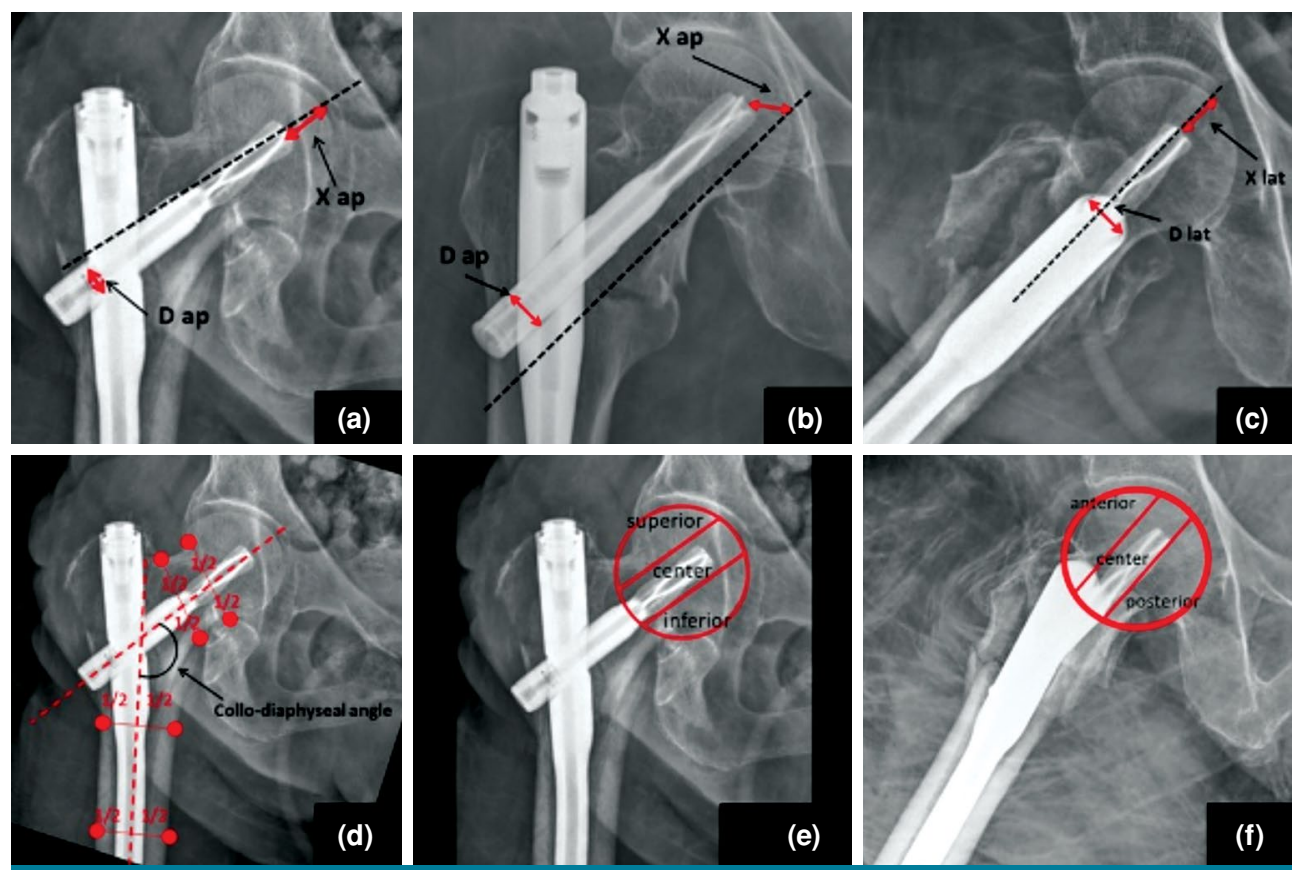

FIGURE 2. (a) Measurement method of TAD on AP radiograph. (b) Calcar referenced TAD on AP radiograph. (c) TAD measurement method on lateral radiograph. (d) Measurement method of collo-diaphyseal angle. (e, $\mathbf{f})$ Determination of quadrants. TAD =[Xap x (D true/Dap)]+[Xlat x (Dtrue/ Dlat)] ( $D$ true: Known true diameter of the helical blade).

TAD: Tip-apex distance; AP: Anteroposterior.

\section{Statistical analysis}

Statistical analysis was performed using the PASW version 17.0 software (SPSS Inc., Chicago, IL, USA). Mean values of the TAD and CDAs were calculated for each quadrant. Normality of the data was assessed by Shapiro-Wilk test. For the continuous data, t-test was used for comparison if the distribution was normal. Mann-Whitney $U$ test was used if the data were not normally distributed. Chi-squared test was used for the comparison of categorical data. A $p$ value below 0.05 was accepted as the statistical significance.

\section{RESULTS}

Cut-out complication was observed in 19 (4.8\%) patients (Figure 3). Mean age of the patients who experienced and not experienced cut-out complication was 78.8 \pm 7.1 (range, 64 to 88 ) years and $75.3 \pm 13.7$ (range, 20 to 101) years, respectively $(\mathrm{p}=0.52)$. There

\section{TABLE I}

Different scenarios according to stability of fracture, tip-apex distance, and quality of reduction

\begin{tabular}{|clccc} 
Scenario number & Included patients & $\begin{array}{c}\text { Number of } \\
\text { patients }\end{array}$ & $\begin{array}{c}\text { Number (\%) of } \\
\text { cut-out patients }\end{array}$ \\
\hline 1 & Unstable, tip-apex distance $\uparrow 25 \mathrm{~mm}$, acceptable-good reduction * & 97 & 4 & 4.1 \\
2 & Unstable, tip-apex distance $\uparrow 25 \mathrm{~mm}$, poor reduction * & 19 & 4 & 21.1 \\
3 & Unstable, tip-apex distance $\downarrow 25 \mathrm{~mm}$, acceptable-good reduction * & 111 & 4 & 3.6 \\
4 & Unstable, tip-apex distance $\downarrow 25 \mathrm{~mm}$, poor reduction * & 17 & 1 & 5.9 \\
5 & Stable, tip-apex distance $\downarrow 25 \mathrm{~mm}$, poor reduction * & 7 & 0 & 0 \\
6 & Stable, tip-apex distance $\downarrow 25 \mathrm{~mm}$, acceptable-good reduction * & 76 & 1 & 1.3 \\
7 & Stable, tip-apex distance $\uparrow 25 \mathrm{~mm}$, poor reduction * & 13 & 3 & 23.1 \\
8 & Stable, tip-apex distance $\uparrow 25 \mathrm{~mm}$, acceptable-good reduction * & 52 & 2 & 3.8
\end{tabular}




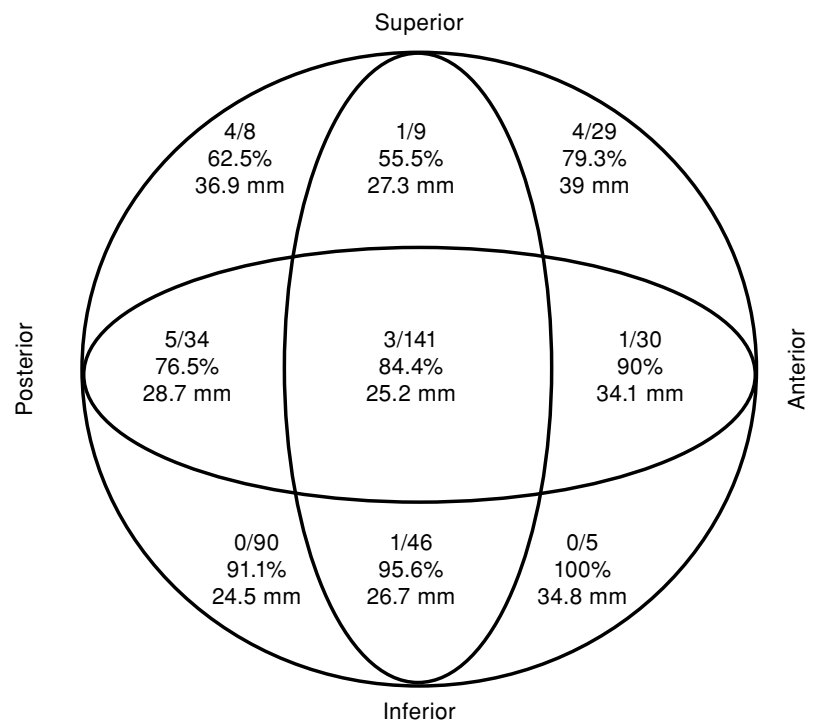

FIGURE 3. Distribution of number of patients according to quadrants. Numbers written in each quadrant from top to bottom represent number of patients with cut-out complication/total number of patients, percentage of acceptable and good reductions according to Baumgaertner criteria, mean tip-apex distance value.

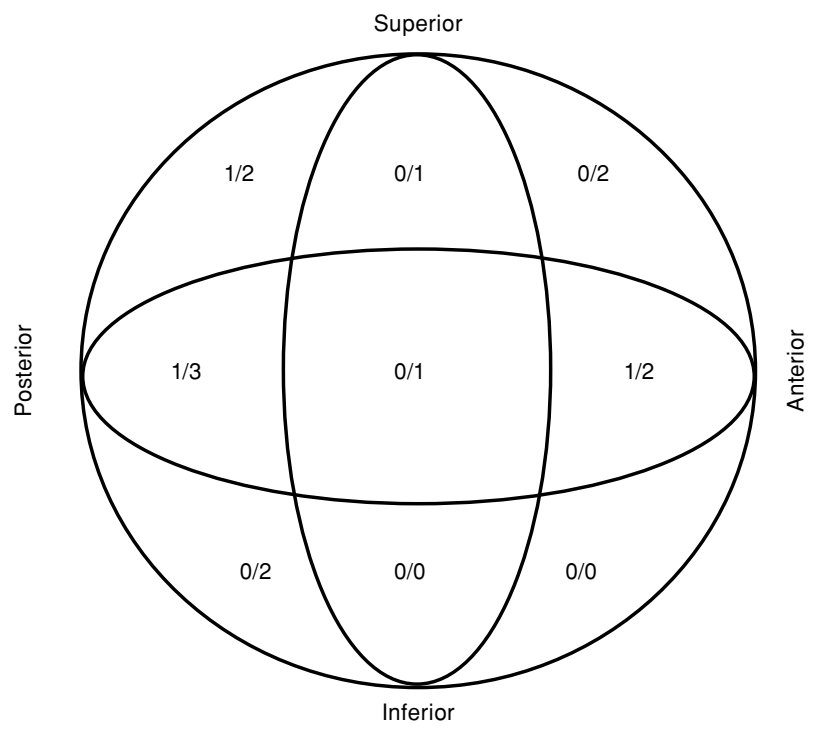

FIGURE 4. Distribution of number of patients with stable, tip-apex distance $\uparrow 25 \mathrm{~mm}$, and poor reduction according to Baumgaertner criteria in each quadrant. Number written in each quadrant represents number of patients with cut-out complication/total number of patients.

were no cut-out complications in patients who were excluded because of radiographs with low quality. One hundred and ninety-eight $(50.5 \%)$ of the fractures were left sided. One hundred and fifty-four (39.3\%) of the fractures were classified as stable according

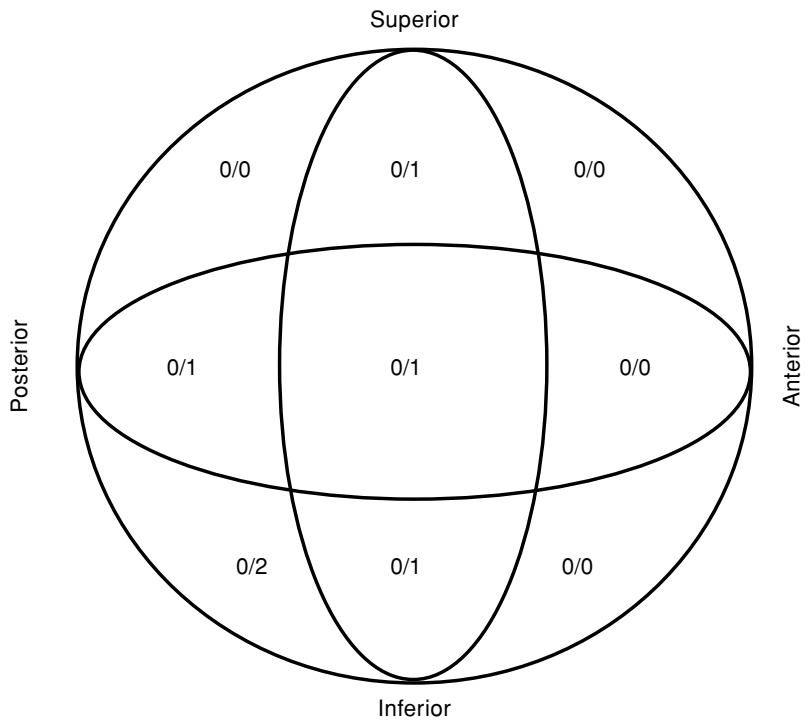

FIGURE 5. Distribution of number of patients with stable, tip-apex distance $\downarrow 25 \mathrm{~mm}$, and poor reduction according to Baumgaertner criteria in each quadrant. Number written in each quadrant represents number of patients with cut-out complication/total number of patients.

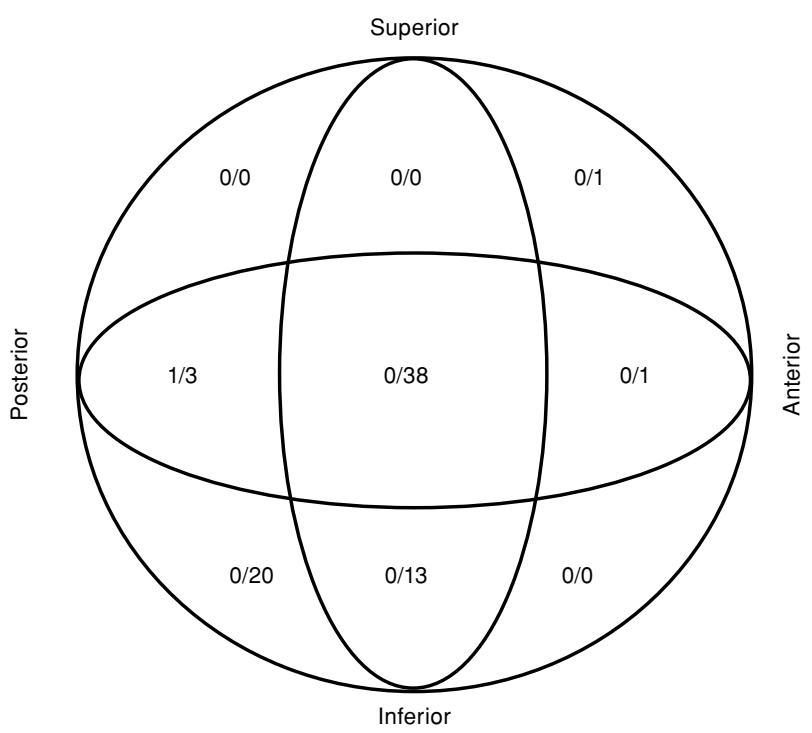

FIGURE 6. Distribution of number of patients with stable, tip-apex distance $\downarrow 25 \mathrm{~mm}$, and acceptable or good reduction according to Baumgaertner criteria in each quadrant. Number written in each quadrant represents number of patients with cut-out complication/total number of patients.

to the OTA classification. Obtained TAD was mean $27.6 \pm 10.8$ (range, 4 to 64 ) $\mathrm{mm}$. Measured TAD was higher than $25 \mathrm{~mm}$ in $182(46.4 \%)$ patients. Mean CDA after the fixation was measured as $133.9^{\circ} \pm 7.4$ (range, 110 to $\left.156^{\circ}\right)$. Sixty-five $(16.6 \%)$ of these reductions 


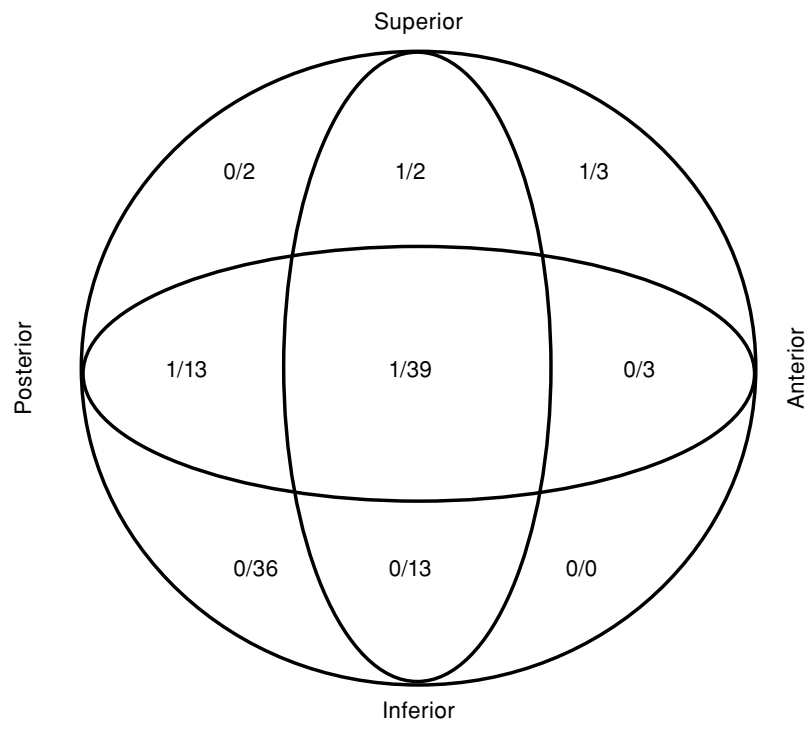

FIGURE 7. Distribution of number of patients with unstable, tip-apex distance $\downarrow 25 \mathrm{~mm}$, and acceptable or good reduction according to Baumgaertner criteria in each quadrant. Number written in each quadrant represents number of patients with cut-out complication/total number of patients.

were evaluated as in varus position (CDA below than $130^{\circ}$ ). The reductions were evaluated as good in $294(75 \%)$, acceptable in $42(10.7 \%)$, and poor in 56 (14.3\%) patients according to Baumgaertner criteria. Cut-out complication was most observed in patients with superior-posterior quadrant localization (4/8-50\%). Highest mean TAD was obtained in the superior-anterior quadrant ( $39 \mathrm{~mm}$ in average). In the most common scenario for cut-out complication; the fracture was stable, TAD was $\uparrow 25 \mathrm{~mm}$ and the reduction was poor (3/13-23.1\%) (Table I and Figure 4). The safest scenarios among cut-out complications were where, regardless of the reduction quality, the TAD was below $25 \mathrm{~mm}$ and the fracture was stable (Table I and Figures 5, 6).

The third scenario (unstable, TAD $\downarrow 25 \mathrm{~mm}$, acceptable or good reduction) was evaluated as the most appropriate scenario to evaluate the importance of quadrant choice in minimalizing the risk of cutout (Figure 7). In this scenario, there were four patients who experienced cut-out complication (3.6\%) (one in center-posterior, one in center-center, one in superior-anterior, and one in superior-center quadrants). There was no statistically significant difference in the risk of cut-out complication occurrence between center-center, inferior-center, and inferior-posterior quadrants $(\mathrm{p}=0.49)$. Mean TAD was less than $25 \mathrm{~mm}$ only in the inferior-posterior quadrant. Reductions were all acceptable or good

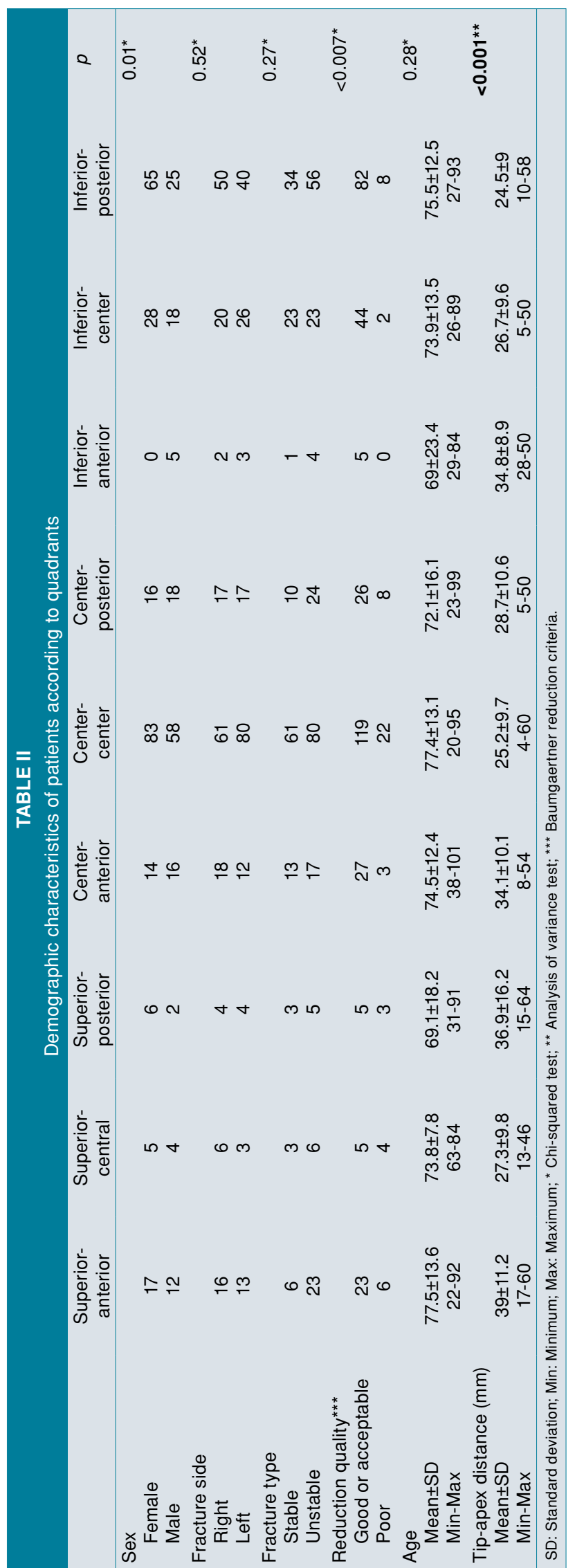


when higher than $90 \%$ if the head-neck fixing device was in the inferior quadrants (Figure 3). Demographic characteristics of the patients according to the quadrants are given in Table II.

\section{DISCUSSION}

Intertrochanteric fractures are very common in the elderly. The elderly population is increasing steadily, making treatment of these fractures much more important in terms of medical, social, and economical issues. Surgical management of ITF in elderly population is challenging and complications related to surgery can be devastating. Mechanical complications are the most common causes of morbidity after these fractures, with cut-out being the most relevant one. ${ }^{[2]}$ Causes of implant cut-out have been shown to be related to osteoporosis, instability of the fracture, the suboptimal fracture reduction, and the non-ideal femoral head lag screw positioning. ${ }^{[19]}$ Surgical management is usually the first-choice treatment option for elderly patients, but it is not an easy procedure to perform and its complications can be disastrous. The hypothesis of this study was that inferior-posterior quadrant is also as safe as center-center and inferior-center quadrants, which are widely recommended. The results of the study confirmed the hypothesis, and the observed result was that inferior-posterior quadrant was as safe as center-center and inferior-center quadrants.

Cut-out complication rate has been reported up to $6.8 \%$ in the literature. ${ }^{[2,20]}$ Historically, this complication rate was much more highly reported which is about $16 \%{ }^{[20]}$ As a result of these high failure rates, the helical blade was designed with the intent of providing stronger fixation by compaction of the cancellous bone as the helical blade is inserted. The blade may also be more effective in supporting torsional load, thereby making it more forgiving to less precise placement in the femoral head. As a result, cut-out rates decreased with probably improved implant designs and surgeons' awareness of modifiable factors to prevent cut-out and being more careful about this issue. The cut-out complication rate in our study population was $4.8 \%$ which is compatible with the current literature. ${ }^{[2]}$

A general consensus is that the appropriate position of the lag screw should be central on the lateral view $^{[4-6,9,21]}$ and either central ${ }^{[4,5]}$ or inferior on the anterior-posterior view. ${ }^{[5,6,9,21]}$ Accordingly, in clinical practice, surgeons always aim to insert the helical blade in central-central or inferior-central quadrants, in the same fashion as the lag screw applications. However, as we hypothesized that inferior-posterior quadrant placement should also be beneficial in terms of obtaining mechanical stability, in the last four years, we strived to insert the helical blade in inferior-posterior quadrants. We recognized that there were no clinical studies which report the inferior-posterior quadrant as a safe localization for head-neck fixing device. ${ }^{[22,23]}$ Among the studies evaluating the results of centralcentral or inferior-central application of the helical blade, a few inferior-posterior application cases were specified, and cut-out was not observed in these cases as we hypothesized so. ${ }^{[24-26]}$

Lee et al. ${ }^{[27]}$ performed an evaluation of the biomechanical effect of different blade positions on a simulated pertrochanteric fracture by means of a computed tomography-based three-dimensional finite element model. They revealed that inferior and posterior blade positions had the larger area of compressive strain at the fracture surface than other three positions. Generally, normal compressive strain was found to be beneficial for the bone healing process. ${ }^{[28]}$ The results suggested that the inferior position could be an ideal choice, while the posterior position would be acceptable as well. Our results also showed that posteriorly positioning of the blade did not cause any complications. Because the lower extremity tends to externally rotate and head-neck fragment tends to go into varus, positioning the implant inferiorly and posteriorly in the femoral head should be advantageous. This will increase the distance and bone stock that the helical blade will travel to cut-out through the femoral head.

The helical blade is an important part of the PFNA. Two major types of implant-related complications have been reported with the PFNA: perforation of the helical blade through the superior cortex of the femoral head or neck, followed by rotation and varus collapse of the head-neck fragment (cut-out); and medial migration of the blade, with perforation of the blade tip into the hip joint without loss of reduction (cut-through). ${ }^{[29]}$ The most common mechanism of cut-through is placement of the helical blade too close to the subchondral bone. ${ }^{[30]}$ In our study group, patients with cut-through complications $(n=6)$ were excluded because the main study question was about the mechanical failure of helical blade. Cut-through complication is mainly related to the close positioning of the helical blade to the articular surface.

Correct implant choice and correct surgical technique were most important surgeon dependent 
factors which directly influence the success of surgical treatment of ITF. In our past study, the importance of these factors in preventing mechanical complication such as cut-out were evaluated in detail. ${ }^{[2]}$ In the study, the three most important factors in preventing cut-out complication after multivariate regression analysis were avoiding varus reduction, insertion of the helical blade in a suitable quadrant, and the TAD being equal to or under $25 \mathrm{~mm}$, respectively. However, it should be noted that in that study, center-center and inferior-center placements were accepted as the appropriate quadrants based on the literature information of that period. In this present study, the effects of factors such as TAD and reduction quality on prevention of cut-out complication were not evaluated since the primary aim of the study was evaluating the importance of quadrant placement of the helical blade in prevention of mechanical complications. Because the quadrants were the primary research subject, the patients with an unstable fracture pattern, obtained TAD $\leq 25 \mathrm{~mm}$, and acceptable or good reductions were included in the final evaluation for standardization and evaluation of the importance of quadrants only.

Although it is well known that center-center and inferior-center positioning of the helical blade is recommended, our study's results showed that inferior-posterior positioning is also very safe. We recommend to orthopedic surgeons that if the inserted guide wire is in the inferior-posterior quadrant, they should not pull back the wire and continue with this wire. Repeated attempts for the insertion of the guide wire may weaken the cancellous structure of the femoral head and also can cause additional harm due to increased exposure to radiation.

This study has some limitations, first being the retrospective design. Secondly, one of the most significant factors about mechanical failure may be the low quality of the bone and this important factor could not be evaluated in this study. Also, the limited sample size is another limitation.

In conclusion, inferior-posterior placement is as adequate as central-central or inferior-central placement for blade fixation in the surgical treatment of ITF. Properly designed, adequately powered randomized control trials are needed to draw stronger conclusions.

\section{Declaration of conflicting interests}

The authors declared no conflicts of interest with respect to the authorship and/or publication of this article.

\section{Funding}

The authors received no financial support for the research and/or authorship of this article.

\section{REFERENCES}

1. Oh JK, Hwang JH, Sahu D. Nailing of intertrochanteric fractures: review on pitfalls and technical tips. JOTR 2010;14:3-7.

2. Turgut A, Kalenderer Ö, Karapınar L, Kumbaracı M, Akkan HA, Ağuş H. Which factor is most important for occurrence of cutout complications in patients treated with proximal femoral nail antirotation? Retrospective analysis of 298 patients. Arch Orthop Trauma Surg 2016;136:623-30.

3. Cleveland M, Bosworth DM, Thompson FR, Wilson HJ Jr, Ishizuka T. A ten-year analysis of intertrochanteric fractures of the femur. J Bone Joint Surg [Am] 1959;41:1399-408.

4. Baumgaertner MR, Curtin SL, Lindskog DM, Keggi JM. The value of the tip-apex distance in predicting failure of fixation of peritrochanteric fractures of the hip. J Bone Joint Surg [Am] 1995;77:1058-64.

5. Kane P, Vopat B, Heard W, Thakur N, Paller D, Koruprolu $\mathrm{S}$, et al. Is tip apex distance as important as we think? A biomechanical study examining optimal lag screw placement. Clin Orthop Relat Res 2014;472:2492-8.

6. Goffin JM, Pankaj P, Simpson AH. The importance of lag screw position for the stabilization of trochanteric fractures with a sliding hip screw: a subject-specific finite element study. J Orthop Res 2013;31:596-600.

7. Liu W, Zhou D, Liu F, Weaver MJ, Vrahas MS. Mechanical complications of intertrochanteric hip fractures treated with trochanteric femoral nails. J Trauma Acute Care Surg 2013;75:304-10.

8. Aguado-Maestro I, Escudero-Marcos R, García-García JM, Alonso-García N, Pérez-Bermejo D D, Aguado-Hernández $\mathrm{HJ}$, et al. Resultados y complicaciones de la osteosíntesis de fracturas pertrocantéreas de fémur mediante clavo endomedular con espiral cefálica (clavo femoral proximal antirrotación) en 200 pacientes [Results and complications of pertrochanteric hip fractures using an intramedullary nail with a helical blade (proximal femoral nail antirotation) in 200 patients]. Rev Esp Cir Ortop Traumatol 2013;57:201-7.

9. De Bruijn K, den Hartog D, Tuinebreijer W, Roukema G. Reliability of predictors for screw cutout in intertrochanteric hip fractures. J Bone Joint Surg [Am] 2012;94:1266-72.

10. Sadic S, Custovic S, Jasarevic M, Fazlic M, Smajic N, Hrustic A, et al. Proximal femoral nail antirotation in treatment of fractures of proximal femur. Med Arch 2014;68:173-7.

11. Güven M, Yavuz U, Kadioğlu B, Akman B, Kilinçoğlu V, Unay $\mathrm{K}$, et al. Importance of screw position in intertrochanteric femoral fractures treated by dynamic hip screw. Orthop Traumatol Surg Res 2010;96:21-7.

12. Kaufer H, Matthews LS, Sonstegard D. Stable fixation of intertrochanteric fractures. J Bone Joint Surg Am 1974;56:899-907.

13. Rubio-Avila J, Madden K, Simunovic N, Bhandari M. Tip to apex distance in femoral intertrochanteric fractures: a systematic review. J Orthop Sci 2013;18:592-8.

14. Mingo-Robinet J, Torres-Torres M, Martínez-Cervell C, Alonso Del Olmo JA, Rivas Laso JA, Aguado-Hernández H, et al. Comparative study of the second and third generation of gamma nail for trochanteric fractures: review of 218 cases. J Orthop Trauma 2015;29:e85-90.

15. Herman A, Landau Y, Gutman G, Ougortsin V, Chechick A, Shazar N. Radiological evaluation of intertrochanteric fracture fixation by the proximal femoral nail. Injury 2012;43:856-63. 
16. Marsh JL, Slongo TF, Agel J, Broderick JS, Creevey W, DeCoster TA, et al. Fracture and dislocation classification compendium - 2007: Orthopaedic Trauma Association classification, database and outcomes committee. J Orthop Trauma 2007;21(10 Suppl):S1-133.

17. Lindskog DM, Baumgaertner MR. Unstableintertrochanteric hip fractures in the elderly. J Am Acad Orthop Surg 2004;12:179-90.

18. Kashigar A, Vincent A, Gunton MJ, Backstein D, Safir O, Kuzyk PR. Predictors of failure for cephalomedullary nailing of proximal femoral fractures. Bone Joint J 2014;96B:1029-34.

19. Mavrogenis AF, Panagopoulos GN, Megaloikonomos PD, Igoumenou VG, Galanopoulos I, Vottis CT, et al. Complications After Hip Nailing for Fractures. Orthopedics 2016;39:e108-16.

20. Ciufo DJ, Zaruta DA, Lipof JS, Judd KT, Gorczyca JT, Ketz JP. Risk Factors Associated With Cephalomedullary Nail Cutout in the Treatment of Trochanteric Hip Fractures. J Orthop Trauma 2017;31:583-8.

21. Kuzyk PR, Zdero R, Shah S, Olsen M, Waddell JP, Schemitsch EH. Femoral head lag screw position for cephalomedullary nails: a biomechanical analysis. J Orthop Trauma 2012;26:414-21.

22. Atik OŞ. Is there something new and interesting in my article? Eklem Hastalik Cerrahisi 2019;30:69.

23. Atik OŞ. What are the expectations of an editor from a scientific article? Jt Dis Relat Surg 2020;31:597-8.

24. Müller F, Doblinger M, Kottmann T, Füchtmeier B. PFNA and DHS for AO/OTA 31-A2 fractures: radiographic measurements, morbidity and mortality. Eur J Trauma Emerg Surg 2020;46:947-53.

25. Jiamton C, Boernert $K$, Babst R, Beeres FJP, Link BC. The nail-shaft-axis of the of proximal femoral nail antirotation (PFNA) is an important prognostic factor in the operative treatment of intertrochanteric fractures. Arch Orthop Trauma Surg 2018;138:339-49.

26. Turgut A, Kalenderer Ö, Günaydın B, Önvural B, Karapınar L, Ağuş H. Fixation of intertrochanteric femur fractures using Proximal Femoral Nail Antirotation (PFNA) in the lateral decubitus position without a traction table. Acta Orthop Traumatol Turc 2014;48:513-20.

27. Lee PY, Lin KJ, Wei HW, Hu JJ, Chen WC, Tsai CL, et al. Biomechanical effect of different femoral neck blade position on the fixation of intertrochanteric fracture: a finite element analysis. Biomed Tech (Berl) 2016;61:331-6.

28. Augat P, Burger J, Schorlemmer S, Henke T, Peraus M, Claes L. Shear movement at the fracture site delays healing in a diaphyseal fracture model. J Orthop Res 2003;21:1011-7.

29. Brunner A, Büttler M, Lehmann U, Frei HC, Kratter R, Di Lazzaro $\mathrm{M}$, et al. What is the optimal salvage procedure for cut-out after surgical fixation of trochanteric fractures with the PFNA or TFN?: A multicentre study. Injury 2016;47:432-8.

30. Nikoloski AN, Osbrough AL, Yates PJ. Should the tip-apex distance (TAD) rule be modified for the proximal femoral nail antirotation (PFNA)? A retrospective study. J Orthop Surg Res 2013;8:35. 